\title{
Individual and couple decision behavior under risk: evidence on the dynamics of power balance
}

\author{
André de Palma - Nathalie Picard . \\ Anthony Ziegelmeyer
}

Published online: 24 October 2009

(C) The Author(s) 2009. This article is published with open access at Springerlink.com

\begin{abstract}
This article reports results of an experiment designed to analyze the link between risky decisions made by couples and risky decisions made separately by each spouse. We estimate both the spouses and the couples' degrees of risk aversion, we assess how the risk preferences of the two spouses aggregate when they make risky decisions, and we shed light on the dynamics of the decision process that takes place
\end{abstract}

Electronic supplementary material The online version of this article (doi:10.1007/s11238-009-9179-6) contains supplementary material, which is available to authorized users.

A. de Palma

Ecole Normale Supérieure de Cachan, 61 Avenue du Président Wilson, 94230 Cachan, France e-mail: andre.depalma@ens-cachan.fr

\section{A. de Palma}

Institut Universitaire de France, Paris, France

A. de Palma $\cdot$ N. Picard

Ecole Polytechnique, Palaiseau, France

N. Picard

THEMA, University of Cergy-Pontoise, 33, Bd du Port, 95011 Cergy-Pontoise Cedex, France

e-mail: nathalie.picard@u-cergy.fr

N. Picard

INED, 133 Boulevard Davout, Paris, France

\section{A. Ziegelmeyer $(\varangle)$}

Strategic Interaction Group, Max Planck Institute of Economics, Kahlaische Str. 10, 07745 Jena, Germany

e-mail: ziegelmeyer@econ.mpg.de

\section{A. Ziegelmeyer}

Faculty of Economics and Management, Technical University of Berlin, Straße des 17 Juni 135, 10623

Berlin, Germany 
when couples make risky decisions. We find that, far from being fixed, the balance of power within the household is malleable. In most couples, men have, initially, more decision-making power than women but women who ultimately implement the joint decisions gain more and more power over the course of decision making.

\section{Keywords Balance of power $\cdot$ Experiments $\cdot$ Household decision-making $\cdot$ Risk}

\section{Introduction}

Almost every important economic decision involves risk, and a substantial body of research investigates how individuals incorporate risk into their decision process. In this body of literature, only a tiny portion is devoted to the study of household decision-making under risk. However, in many day-to-day life contexts such as financial investments, insurance, retirement plans, or residential location, the decisions have consequences at the household level rather than at the individual level. These decisions are (or should be) made jointly. Even when these decisions are formally made by only one member of the household, they may modify (and/or can be modified by) other decisions in the household.

A growing literature in economics shows that household savings and financial investments are significantly affected by how decision-making power is allocated between men and women. ${ }^{1}$ This empirical work observes household outcomes and changes in members' incomes to draw conclusions about underlying gender preferences. As argued below, we strongly believe that this evidence should be interpreted with caution and that such empirical results are not necessarily reflective of intrinsic or immutable preference differences between women and men. In order to identify the link between risky decisions made by couples and risky decisions made separately by each spouse, we use an experimental approach. We observe intra-household financial decisions in an artifactual field experiment. ${ }^{2}$ Our experiment was explicitly designed to investigate the decision process that takes place when couples make risky decisions. ${ }^{3}$

Until recently, household decisions were treated in the standard neoclassical framework of economic theory. This approach corresponds to the unitary model, which

\footnotetext{
1 For example, income given to women is more likely to be used for investments in education and housing than income given to men (Duflo 2003).

2 An artifactual field experiment is identical to a typical laboratory experiment but one which makes use of a non-standard subject pool (see the terminology of Harrison and List 2004).

3 Though there exists copious experimental evidence on how individuals choose, there has been very little experimental investigation into how households or couples make their decisions. Bateman and Munro (2005) present results of an experiment designed to investigate the extent to which decisions made by couples and decisions made separately by spouses are consistent with the axioms of Expected Utility Theory (EUT). They find that choices made by couples exhibit the same kinds of patterns (e.g., the common ratio and common consequence effects) as are regularly recorded with individuals. Bateman and Munro (2009) report on a choice experiment using reductions in dietary health risks as the vehicle. In one treatment, a random individual is chosen from the couple and takes part in a face-to-face interview; in the other treatment, both partners are asked questions jointly, again in a face-to-face interview. They find significant differences in the values elicited in the two treatments, and the values elicited from couples are not a simple average of those elicited from men and women.
} 
involves a unique decision-maker representing the household. From a methodological point of view, unitary models are open to criticism, since they hide the divergences of interest that may arise among household members. Unitary models implicitly assume that the household's members pursue consensual objectives. However, individual preferences cannot be easily aggregated. As pointed out by Chiappori (1988), joint decision making has a different meaning within a couple than in other contexts such as professional interactions. A poor understanding of decision mechanisms (and therefore, of resources allocation within the household) may introduce biases at the descriptive level (interpretation of empirical results) and at the normative level (optimal taxation of households). Further emphasis on the bargaining process in which men and women interact can shed greater light on how individual incomes turn into household outcomes.

The main differences between couples (or more generally families) and other groups are that (i) a large degree of altruism usually takes place within the couple, and (ii) spouses usually have more occasions and willingness to share information. In riskless situations, Chiappori (1988) assumes that the utility of a family is a weighted average of the utilities of its members; the (endogenous) weights depend on all individual characteristics and reflect the respective bargaining powers of each member in the household. Chiappori's approach amounts to assume that the negotiation leads to a Pareto-optimal solution, which is consistent with any efficient negotiation process. The weights of each spouse's utility are then called Pareto weights. If the Pareto weights are constant (i.e., do not depend on any individual or family characteristics such as wages or individual wealths), then the family can be represented by a single standard utility function. This corresponds to the (above mentioned) unitary approach, which ignores the various decision-making processes and transactions occurring among the household members. Unitary models imply the income pooling condition: decisions made by the family should not be affected by the source of income or wealth.

On the contrary, if the Pareto weights are not constant, then bargaining powers change with individual wages or wealths. In this case, there is no simple and intuitive relation between the spouses' and the couple risk aversions. Income pooling has been repeatedly rejected empirically in different cultural contexts (Vermeulen 2002). Therefore, more and more studies (both theoretical and empirical) concerned with couple decisions in a deterministic environment are now written within the collective framework (à la Chiappori).

When risk dimensions are involved in the decision process, most of the literature still relies on the unitary approach. Among the very few exceptions is Mazzocco (2004) who shows that, in a collective model, an increase in the degree of risk aversion of one household member may induce the household to take more risk (see also Donni 2003). This counter-intuitive phenomenon results from the opposing impacts of individual degrees of risk aversion on individual decisions and Pareto weights. Indeed, the Households Retirement Survey data show that the risk aversion of couples in which the woman's risk aversion is very high, and is a $U$-shaped function of the man's risk aversion.

This article reports on an experimental test of couple decision-making under risk. Couples are presented with tasks involving binary choices between a lottery and a sure payoff. In the first part of the experiment, spouses are separated and choose indepen- 
dently. In the second part of the experiment, male spouses rejoin their partner and they make joint decisions. Couples are video-recorded while interacting and discussing to make joint decisions. We estimate both the spouses and the couples' degrees of risk aversion, we assess how the risk preferences of the two spouses aggregate when they make risky decisions, and we shed light on the dynamics of the decision process that takes place when couples make risky decisions. We find that, far from being fixed, the balance of power within the household is malleable. In most couples, men have, initially, more decision-making power than women but women who ultimately implement the joint decisions gain more and more power over the course of decision making.

The road map of the article is as follows. Section 2 describes our experimental design. In Sect. 3, we first provide ordinal measures of couples and spouses risk aversion, and then we investigate the dynamics of power balance using discrete choice models techniques. A quantitative analysis of the couples discussions is provided in Sect. 4. Finally, Sect. 5 concludes.

\section{Experimental design}

We elicited measures of risk aversion by means of choice bracketing procedures, also referred to as investment series. In each step of the bracketing procedure, the decision maker (either an individual or a couple) had to choose between a safe and a risky alternative. Risky alternatives were simple monetary lotteries, modeling the toss of a fair coin, i.e., yielding a low (respectively high) payoff with probability $1 / 2$. Potential payoffs and probabilities were always known to the decision makers and, in a given bracketing procedure, the safe alternative was a sure amount ranging from the low outcome of the lottery to the high outcome of the lottery. At the end of the experimental session, one of the steps was randomly selected for payoff, and the decision maker's chosen option was then played out as the reward. ${ }^{4}$ All details concerning the bracketing procedures and the lotteries are to be found in the Supplementary Material. ${ }^{5}$

Our elicitation method has two main advantages: First, we expect it to provide reliable estimates of risk aversion due to the simplicity of the task and the transparency of the incentives to respond truthfully; Second, it enables us to directly infer a risk attitude from the pattern of the decision maker's responses in a given investment series (see Sect. 3.1). The main disadvantage of our elicitation instrument is that it cannot be used to make inferences about non-EUT models of choice behavior. As we restrict probabilities to $1 / 2$, we cannot use the decision maker's responses to make inferences

\footnotetext{
4 The random lottery incentive system avoids income and house money effects, and it has become the almost exclusively used incentive system in individual decision-making experimental studies today. Holt (1986) argued that if subjects do not separate each task under this incentive system, then it would lead them to a different behavior from that in a single-shot task. However, several experimental studies demonstrate that the random lottery incentive system induces an almost identical behavior to that in a single-shot task (Starmer and Sugden 1991; Cubitt et al. 1998; Hey and Lee 2005).

5 Our elicitation method is remotely related to the Random Lottery Pairs design which has been generally used to test the predictions of EUT (see, among others, Hey and Orme 1994). The main differences are that probabilities were always equal to $1 / 2$ in our design, and one of the two alternatives was a safe option.
} 
about probability weighting, which plays a major role in rank-dependent alternatives to EUT. Consequently, we default to thinking of risk attitudes as synonymous with the properties of the utility function, consistent with traditional EUT representations.

\subsection{Experimental sessions and participants}

Seven experimental sessions were carried out from January 2005 to February 2005. Subjects were recruited from the city of Jena (Germany) via local newspaper advertisements, through community groups, and using posters in the city center. Session sizes varied from 2 to 4 couples, and were held at the experimental economics video laboratory of the Max Planck Institute of Economics in Jena. In recruiting, we required all individuals to be over 30 , to be living with their partners and to have been together as a couple for at least one year. We recruited 22 couples for our experiment. They answered to a total of 3,828 lotteries (either individually or with their spouse). At the beginning of the experiment, we asked a few warm-up questions to the spouses separately about themselves and about the couple (see step 1 of Sect. 1 in the experimental procedures sum-up below). The main characteristics are briefly summarized now.

Average payoffs were just above $50 €$ per individual-more than five times the median hourly post-tax wage for an adult working in the former East Germany in 2005. Ages ranged from 21 to 64 , with a mean of $43 .{ }^{6}$ Approximately $73 \%$ of individuals stated that they were married to their current partner, and all the couples in our sample were heterosexual. On average, couples had been together for 15 years (median of 17), with a maximum of 42 and a minimum of less than $1 .^{7}$ Interestingly, the union duration stated by women is on average 1 year more than the duration stated by men, with a maximum difference of 12 years. This difference may be explained by the fact that the man only considered marriage duration, whereas the woman considered the total duration, including the period they were living together before they got married. On average, couples had 1.3 children together. In addition, the women (men) had on average 0.3 (respectively 0.5 ) children from previous union(s). These figures are quite representative of the German population (see Lechner 2001).

\subsection{Progress of an experimental session}

Before entering the video laboratory, couples were reminded that decisions would be implemented on computers (this information had already been provided in the invitation mail), and they were told that they could ask for help at any point in time during the experimental session. Couples were also informed that the session would take place in a video laboratory and that part of the session would be video-recorded. ${ }^{8}$

\footnotetext{
6 One couple was below the required age of 30 years. Both were students aged 21-22.

7 Only the couple of students had a union duration of less than one year.

8 Couples were also told that if they did not feel like being recorded, then they could leave immediately and that they would get a compensation of $20 €$ per person. All couples decided to stay and take part in the experiment.
} 
Finally, it was mentioned to the couples that the session would consist of several parts (no details concerning the different parts were provided at that point of time) and that instructions for each part would be delivered in due time.

On entering the video laboratory, couples were separated: each male entered one of the odd numbered cabins and each female entered one of the even numbered cabins. ${ }^{9}$ The experiment involved two sections. The first section was conducted with the two spouses located in different cabins; pairs then rejoined each other for the second section.

The first section of the experiment started with the elicitation of the participants' socioeconomic characteristics (level of education, post-tax monthly salary, etc.). Next, the separated subjects had to estimate their influence on the couple decision in every day life situations. After answering this questionnaire, each subject was endowed with $40 €$. Finally, the separated subjects went through six investment series: in the first three series, separated subjects had to invest part or all of their own endowment into risky options, whereas during the last three series each subject had to invest part or all of the couple endowment into risky options. Before going through the six series of risky investments, subjects were told that they would have to go through 12 investment series and that each of their answers could possibly determine their payoff. ${ }^{10}$ The subjects were given details of how the payout procedures would operate only at the end of the experiment.

In the second section of the experiment, couples made choices jointly, and this section has been video-recorded. Male spouses were asked to join their female partners in their cabin, and choices were made on the computer previously used by the female spouse. Couples went through six investment series. They had the possibility to discuss but no specific instructions as to how the couple decisions should be made were provided (and no explicit time limit was given). Most couples went through the six series of risky investments in less than $15 \mathrm{~min}$, which indicates that agreements were quite easily reached. Except for five couples, the female spouse always physically entered the couple decisions into the computer. It is rather unsurprising that in most cases women implemented the couple decisions since the second section of the experiment took place in the women cabins and couple decisions were made on the same computers women used to make their individual decisions. ${ }^{11}$ Although the

\footnotetext{
9 The experimental economics video laboratory of the Max Planck Institute of Economics in Jena comprises eight soundproof cabins. Each cabin provides in- and out-put for video and audio signals. In addition, each cabin is equipped with a personal computer.

10 Payoff-relevant investments were preceded by a training series of 10 investments.

11 The likelihood that the man implements the couple decisions increases with the income difference between the two spouses. In the five couples in which the man holds the mouse, the average income difference is 3.8 categories. The average income difference is only 1.23 categories in the 17 couples in which the woman holds the mouse. This difference is statistically significant at the $10 \%$ level. In addition, men who hold the mouse are on average 0.4 levels more educated than their wives, and women who hold the mouse are on average 0.47 levels more educated than their husbands. This difference is not statistically significant $(p$-value $>0.1)$.
} 
assignment of the mouse is not induced experimentally, ${ }^{12}$ our experimental design clearly favors women over men for the control of the mouse.

The incentive system was as follows. In the beginning, one of the two spouses had to randomly draw a card from a pile of five cards, one card being numbered one, two cards being numbered two, and two cards being numbered three. If the card numbered one was randomly drawn then the payoff-relevant decision was determined separately for each spouse. Indeed, the payoff-relevant decision for each spouse was randomly selected among the decisions in which the spouse invested part or all of his/her endowment. The male spouse went back to his cabin, and each spouse's paid decision was determined according to two random draws, one random draw to determine the series (series 1,2, or 3) and the other random draw to determine which decision in the series. If a card numbered two was randomly drawn, then the payoff-relevant decision for the couple was determined. First, a random draw decided whether one of the female or one of the male decisions to invest the couple endowment would be paid, and second, two additional random draws were made to select the series (series 4, 5, or 6) and the decision in the randomly selected series. If a card numbered three was randomly drawn, then the payoff-relevant decision for the couple was determined. Two random draws were made to select the series (series 7, 8, 9, 10,11, or 12) and the decision in the randomly selected series.

Our payoff scheme incentivizes subjects to truly reveal their individual preferences in the first part of the experiment unless spouses expect their choices to be undone later at home and/or spouses try to efficiently coordinate their choices with each other. The first possibility is a natural consequence of the fact that our subjects have an ongoing relationship with each other which implies that choices made during the experiment can be undone when spouses go home. Any experimental study on intra-household decision making suffers from this weakness, and we do not know of a satisfactory procedure to handle it. Still, we observed that in all cases where spouses collected money from having invested their personal endowment, earnings were placed in individual wallets immediately after payment (in those cases, spouses were paid in private and not informed about each other's earnings). ${ }^{13}$ Although this evidence is not fully convincing, it suggests the absence of binding agreements on individual earnings. The second possibility relates to the fact that individual incentives in the first three investment series differ, at least theoretically, from those in the next three investment series. Spouses might choose more risky options in investment series 1, 2, and 3 than in investment series 4,5 , and 6 as a result of coordination attempts with their partner since only personal endowments are invested. It seems rather unlikely that such coordination attempts took place. Indeed, spouses were in separate soundproof cabins in the first section of the experiment not being aware of the decision tasks faced by their partner. More importantly, details of how the payout procedures operate were

\footnotetext{
12 Given the nature of our subject pool, we feared that the assignment of the mouse to a specific spouse would be a rather intrusive procedure. In a follow-up study, we investigate an alternative procedure in which both spouses enter the couple decisions into the computer.

13 On the contrary, when spouses earnings were derived from investments of the couple endowment, one spouse always collected the joint earnings as a result of mutual consent even though these earnings had been divided by the experimenters into two equal shares.
} 
provided only at the end of the experiment. Before the start of the experiment, subjects were only told that each of their choices could possibly determine their payoff.

The computer screens that subjects saw while going through the two sections of the experiment have been translated (see the Supplementary Material). Additional material of the experimental sessions, such as the written instructions and the payment procedures, is available on request from the authors. Below, we summarize our experimental procedures.

\section{Experimental procedures}

\section{Section 1 of the experiment: Spouses are separated}

In step 1, each spouse is asked to answer questions concerning his/her personal characteristics as well as concerning the couple characteristics. In the last three steps, each spouse goes through several investment series. In each series, the spouse has to invest a certain amount of money either in a lottery, modeling the toss of a fair coin, or in a sure payoff. Sure payoffs range from the low outcome of the lottery to the high outcome of the lottery.

- Step 1. Characteristics of the individual/couple: First, each spouse is asked to answer questions concerning his/her personal characteristics (age, job status etc.). Second, each spouse is asked to answer questions concerning his/her financial status (income, real estate etc.). Finally, the decision-making power of each spouse in some of the couple decisions is elicited.

After answering all the questions, each spouse collects $40 €$ as a reward.

- Step 2. Training investment series: Each spouse goes through an investment series which is not payoff-relevant. Each investment decision consists in investing $50 €$.

- Step 3. Investment series 1, 2, and 3: Each spouse goes through three payoff-relevant investment series. In the first series, each spouse invests 20 out of the $40 €$ he/she collected. In the second and third series, each spouse invests the entire $40 €$.

- Step 4. Investment series 4,5, and 6: Each spouse goes through three payoff-relevant investment series. In the first series, each spouse invests 40 out of the $80 €$ the couple collected. In the second and third series, each spouse invests the entire $80 €$.

\section{Section 2 of the experiment: Spouses are together}

In step 5, the couple goes through three investment series. In each series, the couple has to invest a certain amount of money either in a lottery, modeling the toss of a fair coin, or in a sure payoff. Sure payoffs range from the low outcome of the lottery to the high outcome of the lottery. In step 6 , the couple goes through three investment series, including 3 questions each. In each series, the couple has to invest a certain amount of money either in a lottery (specific to each question), modeling the toss of a fair coin, or in a sure payoff (which does not vary within a series). In each series, the lottery proposed in the second question depends on the answer to the first question, and the lottery proposed in the third question depends on the answer to the first and second questions.

- Step 5. Investment series 7, 8, and 9: The couple goes through three payoff-relevant investment series. In the first series, the couple invests 40 out of the $80 €$ the couple collected. In the second and third series, the couple invests the entire $80 €$. The figures in series 7 (respectively 8,9 ) are exactly the same as the ones in series 4 (respectively 5,6 ).

- Step 6. Investment series 10, 11, and 12: Both the amount invested and the sure payoff are $80 €$. In the first series, the couple may loose half of the $80 €$ in the worst case and increase their payoff up to $140 €$ in the best case. The expected payoff of all lotteries is $90 €$, and the variability of the payoff is increased if the couple previously selected the lottery, decreased if they previously selected the sure payoff. The second series is similar, except that the safe payoff is $90 €$ (all amounts in the first question are increased by $10 €$ ). In the third series, there is no risk of any loss (the payoff in the worst case is $80 €$ ), and instead of increasing/decreasing the variance, only one outcome is increased/decreased depending on the answer to the previous question. 


\section{Results}

In this section, we first assess the decision makers' degrees of risk aversion by relying on an ordinal approach. We restrict ourselves to the choices made by the spouses separately in investment series 4-6 (Step 4), and to the choices made by the couples in investment series 7-9 (Step 5). Indeed, in investment series 4 (respectively 5 and 6) each spouse is assigned to the same lottery, and this lottery is also the one used in investment series 7 (respectively 8 and 9) when both spouses decide jointly. Therefore, the individual and couple answers can be compared directly. Second, we rely on a cardinal approach, and we assume that spouses are expected utility maximizers with a constant absolute risk aversion utility function. We use individual choices in investment series 1-6 and joint choices in investment series 7-12 to study the evolution of the balance of decision-making power within the household. Both in the cardinal and in the ordinal approach, we allow the choices to violate the assumption that preferences are monotonic with respect to money.

\subsection{Man, woman, and couple risk attitudes}

In each investment series $j$, the decision maker faces 11 choices $(i=1, \ldots, 11)$ between a lottery $L_{j}$ and a sure payoff $S_{j}(i)$. The lottery yields the low payoff $S_{j}(11)$ and the high payoff $S_{j}(1)$ with equal probabilities. The sequence of sure payoffs is given by $S_{j}(i)=S_{j}(11)+\left(\frac{11-i}{10}\right)\left(S_{j}(1)-S_{j}(11)\right), i=1, \ldots, 11$. As the expected value of the lottery equals $S_{j}(6)$, a risk-neutral decision maker is indifferent between the lottery and $S_{j}(6)$.

The set of choices made by a decision maker facing investment series $j$ is inconsistent if monotonic and transitive preferences cannot rationalize those choices. Table 1 shows, for each investment series, the relative frequency of inconsistent sets of choices for women, men, and couples. Altogether, there were 23\% (respectively 13 and 9\%) of inconsistent sets of choices for women (respectively for men and for couples). Most of the women inconsistent sets of choices were made in the early investment series, which suggests that women need more than one training investment series to get acquainted with the task. ${ }^{14}$

A consistent set of choices is characterized by a unique switching point, $i \in$ $\{0, \ldots, 11\}$ : for a given investment series $j$, decision maker $k$ in class $i$ prefers lottery $L_{j}$ to all deterministic amounts lower than or equal to $S_{j}(i+1)$ and prefers all amounts larger than or equal to $S_{j}(i)$ to lottery $L_{j}$. In this case, we denote by $\succ_{k}$ the risk preference relation of decision maker $k$, uniquely defined on the set

\footnotetext{
14 Given the nature of our risk elicitation mechanism and subject pool, the amount of inconsistencies observed is rather low. Experimental studies which have employed a multiple price list (MPL) risk elicitation mechanism report a proportion of inconsistent preferences usually larger than $10 \%$. Among others, both Eckel and Wilson (2004) and Holt and Laury (2002) report $13 \%$ of inconsistent preferences (this proportion drops to $5.5 \%$ when payoffs are scaled by a factor of 50 or 90 in the latter study), and Bruner et al. (2008) report $20 \%$ of inconsistent preferences. Note that these studies used college students as experimental subjects (who are generally quick on understanding their task in the experiment) and that the MPL mechanism allows subjects to see all choices in one frame which might lead them to make more consistent choices than they would otherwise (but seems to induce a framing effect).
} 
Table 1 Relative frequencies of inconsistent series of choice

\begin{tabular}{llll}
\hline Investment series & Woman & Man & Couple \\
\hline 1 (Woman and Man) & $9 / 22$ & $2 / 22$ & \\
2 (Woman and Man) & $7 / 22$ & $3 / 22$ & \\
3 (Woman and Man) & $6 / 22$ & $3 / 22$ & \\
4 (Woman and Man)/7 (Couple) & $2 / 22$ & $3 / 22$ & $2 / 22$ \\
5 (Woman and Man)/8 (Couple) & $2 / 22$ & $2 / 22$ & $1 / 22$ \\
6 (Woman and Man)/9 (Couple) & $4 / 22$ & $4 / 22$ & $3 / 22$ \\
\hline
\end{tabular}

Table 2 The 12 sets of consistent choices

\begin{tabular}{llllllll}
\hline Switching point & Set of consistent choices & \multicolumn{6}{c}{ Investment series: Woman, Man; Couple } \\
\cline { 3 - 8 } & & 1 & 2 & 3 & $4 ; 7$ & $5 ; 8$ & $6 ; 9$ \\
\hline 0 & $L_{j} \succ_{k} S_{j}(1)$ & 1,0 & & & & & \\
1 & $S_{j}(1) \succ_{k} L_{j} \succ_{k} S_{j}(2)$ & & & & & & \\
2 & $S_{j}(2) \succ_{k} L_{j} \succ_{k} S_{j}(3)$ & & & & & & \\
3 & $S_{j}(3) \succ_{k} L_{j} \succ_{k} S_{j}(4)$ & 1,1 & & & & & \\
4 & $S_{j}(4) \succ_{k} L_{j} \succ_{k} S_{j}(5)$ & 0,1 & 0,1 & 0,1 & 1,$0 ; 0$ & 1,$0 ; 0$ & \\
5 & $S_{j}(5) \succ_{k} L_{j} \succ_{k} S_{j}(6)$ & 0,3 & 1,2 & 5,1 & 1,$1 ; 2$ & 1,$1 ; 2$ & 0,$0 ; 1$ \\
6 & $S_{j}(6) \succ_{k} L_{j} \succ_{k} S_{j}(7)$ & 5,7 & 1,3 & 6,8 & 4,$7 ; 6$ & 4,$6 ; 2$ & 6,$7 ; 5$ \\
7 & $S_{j}(7) \succ_{k} L_{j} \succ_{k} S_{j}(8)$ & 1,0 & 2,6 & 1,3 & 4,$5 ; 4$ & 5,$3 ; 0$ & 4,$3 ; 4$ \\
8 & $S_{j}(8) \succ_{k} L_{j} \succ_{k} S_{j}(9)$ & 3,5 & 5,3 & 1,4 & 5,$2 ; 7$ & 2,$6 ; 13$ & 3,$4 ; 5$ \\
9 & $S_{j}(9) \succ_{k} L_{j} \succ_{k} S_{j}(10)$ & & 2,3 & 0,1 & 2,$2 ; 1$ & 2,$2 ; 4$ & 0,$1 ; 4$ \\
10 & $S_{j}(10) \succ_{k} L_{j} \succ_{k} S_{j}(11)$ & 1,0 & 2,0 & 1,1 & 0,$1 ; 0$ & 2,$1 ; 0$ & 1,$1 ; 0$ \\
11 & $S_{j}(11) \succ_{k} L_{j}\left(L_{j}-\mathrm{OR}\right)$ & 1,3 & 2,1 & 2,0 & 3,$1 ; 0$ & 3,$1 ; 0$ & 4,$2 ; 0$ \\
\hline
\end{tabular}

$\left\{L_{j}, S_{j}(i), i=1, \ldots, 11\right\}$ by his/her set of replies to series $j$. More specifically, $S_{j}(i) \succ_{k} L_{j}$ means that decision maker $k$ prefers the sure payoff $S_{j}(i)$ to the lottery $L_{j}$. Given the construction of the series, the classes are ranked by increasing risk aversion, which defines an ordinal measure of risk aversion.

Out of the $2^{11}$ potential sets of choices in a given investment series, only 12 are consistent, which defines 12 ordered classes of risk aversion. They are represented in Table 2, together with the frequencies of observed answers in each series, for women, men, and couples.

We observe that a significant proportion of individuals (especially women) are willing to receive always less money just for the benefit of avoiding any risk (15 out of $22 * 6$ women-series and 8 out of $22 \times 6$ men-series). We denote by Locally Opposed to Risk for lottery $L_{j}\left(L_{j}-\mathrm{OR}\right)$, those decision makers who consistently prefer any sure payoff $S_{j}(i), i=1, \ldots, 11$, to lottery $L_{j}$ in investment series $j . L_{j}$-OR preferences are never shared by both spouses in a couple nor by the two spouses together, i.e., no $L_{j}-\mathrm{OR}$ individual was able to convince his/her spouse. We observe that only one respondent (a female respondent) is $L_{j}-\mathrm{OR}$ for the six series $L_{j}, j=1, \ldots, 6$ which implies an infinite level of risk aversion. 

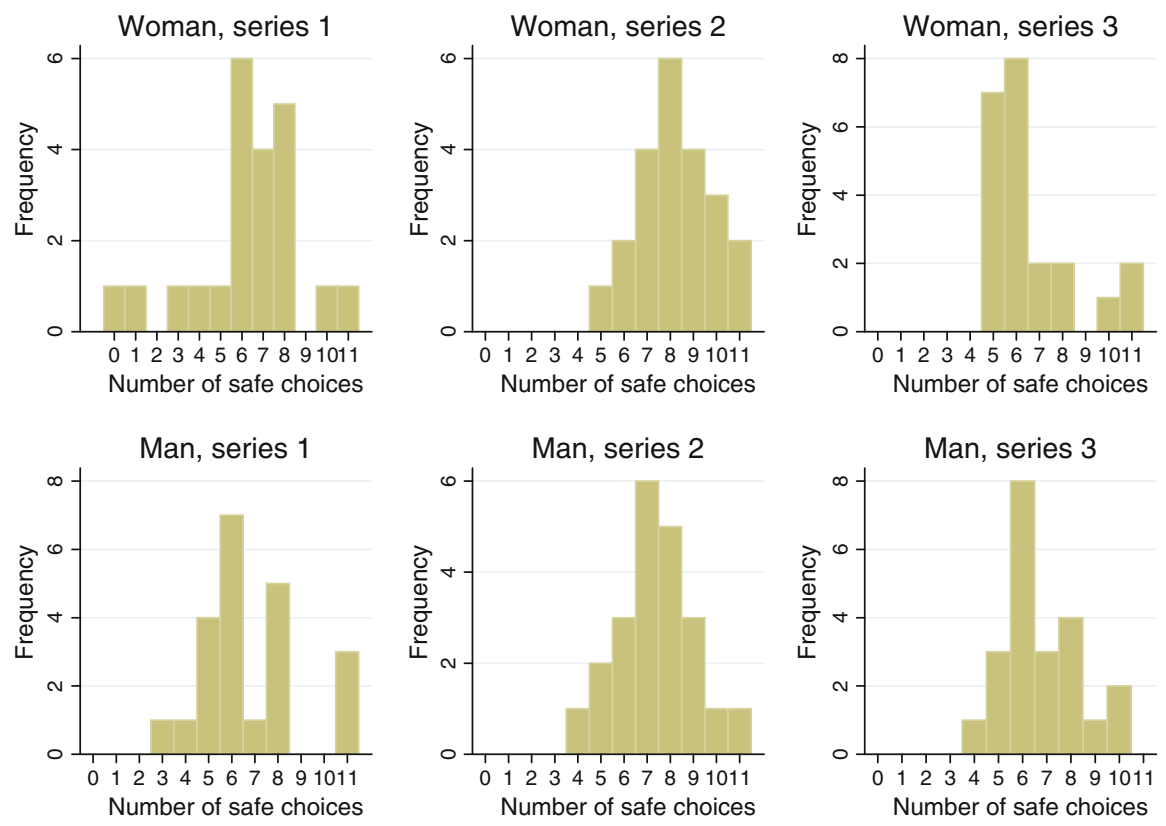

Fig. 1 Empirical distributions of safe choices, individual money

In order to take into account inconsistent sets of choices, the total number of "safe" choices is used as an indicator of risk aversion: for a given investment series, the measure of risk aversion is given by the frequency of choices where the decision maker picks the sure payoff instead of the lottery (in case of consistent series, the same measure is obtained with the switching point). Figure 1 shows the empirical distributions of safe choices in the three investment series concerned with individual money, separately for women and men. Both for women and men, the distribution is more spread for the first series, and some respondents appear extremely risk lovers. This may reflect the fact that one training series was not enough and that some respondents answered randomly in the first series because they were not acquainted with the task.

Figure 2 shows the empirical distributions of safe choices in the three investment series concerned with couple money, separately for women, men, and couples (spouses together). In all three investment series, the distribution of couple choices is more concentrated than the distribution of spouse choices.

Both figures suggest that women are slightly more risk averse than men, and that men and women answers are more heterogeneous than couples answers. This is confirmed in Table 3, which shows the average frequencies of safe choices for the woman, the man and for the couple in the different investment series, as well as their differences.

Concerning investment series 1-3 (individual money), women and men answers cannot be directly compared since the amounts involved were generated randomly, independently for the woman and for the man. Table 3 supports the idea that individuals (especially women) answered more randomly in series 1 , since the average 

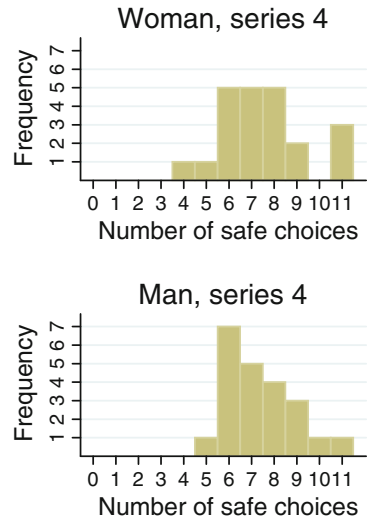

Couple, series 7

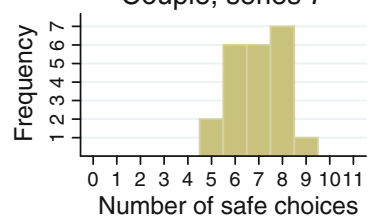

Woman, series 5

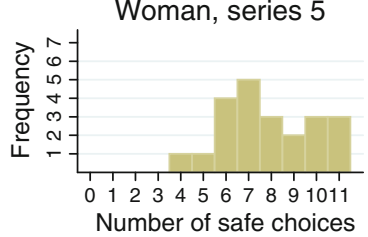

Man, series 5

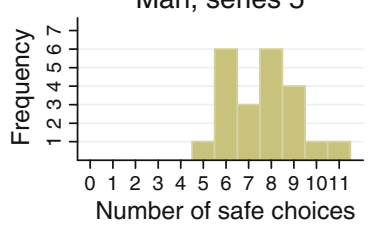

Couple, series 8

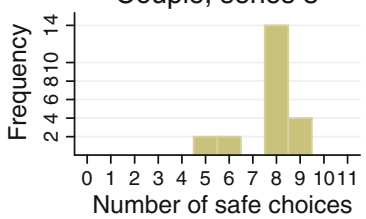

Woman, series 6

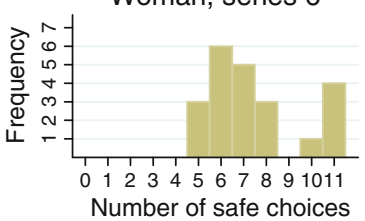

Man, series 6

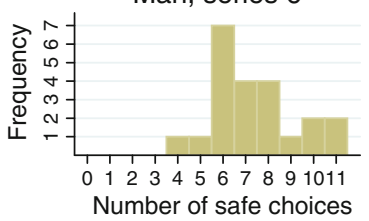

Couple, series 9

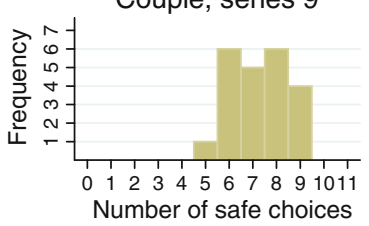

Fig. 2 Empirical distributions of safe choices, couple money

Table 3 Average frequencies of safe choices (standard deviations in parentheses)

\begin{tabular}{lllllrr}
\hline Investment series & Woman & Man & Couple & \multicolumn{2}{l}{ Differences } \\
\cline { 5 - 7 } & & & & Woman-Couple & Man-Couple & Woman-Man \\
\hline 1 & $6.27(2.57)$ & $6.73(2.18)$ & & & & $-0.50(3.69)$ \\
2 & $8.23(1.60)$ & $7.36(1.68)$ & & & & $0.86(2.57)$ \\
3 & $6.59(1.89)$ & $6.77(1.60)$ & & & & $-0.18(2.34)$ \\
$4 / 7$ & $7.50(1.87)$ & $7.36(1.53)$ & $6.95(1.09)$ & $0.55(1.84)$ & $0.41(1.37)$ & $0.14(2.28)$ \\
$5 / 8$ & $7.86(2.03)$ & $7.59(1.53)$ & $7.73(1.16)$ & $0.14(2.21)$ & $-0.14(1.49)$ & $0.27(2.86)$ \\
$6 / 9$ & $7.45(2.06)$ & $7.36(1.89)$ & $7.27(1.20)$ & $0.18(1.92)$ & $0.09(2.14)$ & $0.09(3.00)$ \\
\hline
\end{tabular}

frequency of safe choices is lower ${ }^{15}$ and the standard deviations (of individual answers and of their differences) are larger for series 1 than for series 2 and 3.

Concerning investment series 4-6 (couple money), women are (slightly) more risk averse than men. ${ }^{16}$ Moreover, the average couple tends to be less risk averse than its

\footnotetext{
15 The average would be 5.5 for pure random choices, which is lower than the observed average of $7-8$ for the other series.

${ }^{16}$ Individual answers in investment series 4, 5, and 6 could reflect more the preferences of the couple than individual answers in investment series 1,2, and 3 since individuals invest the couple's money. Our experimental data do not support this argument. Indeed, the correlation factor between the average degree of risk aversion in Step 3 and the average degree of risk aversion in Step 4 is highly positive for both spouses: It equals 0.682 for the woman and 0.574 for the man. These correlation factors are at least as positive as those obtained when comparing the average degrees of risk aversion of different investment series in the same step for a given spouse: In Step 3, the average correlation factor equals 0.419 for the woman and
} 
average members (Munro et al. 2008 report a similar finding). Indeed, the average measure of risk aversion for couples is systematically lower than the average measure of risk aversion for women, and it is lower than the average measure of risk aversion for men in two out of the three investment series. The variance of the difference between men and women measures of risk aversion increases over time. The variance of the difference between the couples and the men measures of risk aversion also increases over time contrary to the variance of the difference between the couples and the women measures of risk aversion which exhibits no monotonic pattern. In conclusion, after controlling for the average difference between women, men, and couples measures of risk aversion, the distance between couples and men measures of risk aversion increases, whereas the distance between couples and women measures of risk aversion remains constant. This suggests that the relative decision-making power of the woman when the couple is facing a unique decision increases over time.

In the next section, we study the evolution of the balance of power within the household, and we relate our findings to the empirical/theoretical literature on intrahousehold decision-making.

\subsection{The balance of power within the household}

We now assume that the preferences of any decision maker in our sample can be represented by a utility function with constant absolute risk aversion (CARA) for money $x>0$ (this choice is based on initial tests for various standard utility functions). Decision maker $k$ 's utility function is, therefore, given by $V_{k}(x)=V\left(x ; \theta_{k}\right)=$ $\left(1-\exp \left(-\theta_{k} x\right)\right) / \theta_{k}$ where $\theta_{k}$ is the level of absolute risk aversion. In investment series $j$, the utility of the safe alternative $S_{j}(i)$ is $V_{k}\left(S_{j}(i)\right)$, while the expected utility of the lottery is given by $\mathbb{E}\left[V_{k}\left(L_{j}\right)\right]=\left(V_{k}\left(S_{j}(1)\right)+V_{k}\left(S_{j}(11)\right)\right) / 2$.

Experimental evidence suggests that stochastic variation is an essential feature of decision-making behavior. ${ }^{17}$ Therefore, we assume that choices made by decision maker $k$ in series $j$ are consistent with an absolute risk aversion level $\tilde{\theta}_{j k}$, a random variable modeled as $\tilde{\theta}_{j k}=a+\mu_{k}+\delta_{j}+\varepsilon_{j k}$ where $a$ is a constant term equal across series and decision makers, $\mu_{k}$ is an decision-maker-specific term with zero mean, $\delta_{j}$ measures potential systematic deviations specific to series $j$ and $\varepsilon_{j k}$ is a normal error term with zero mean and variance specific to series $j$. The variance of $\mu_{k}+\varepsilon_{j k}$ is denoted by $\sigma_{j}^{2}$. We employ an interval regression method to estimate the absolute risk aversion

\footnotetext{
Footnote 16 continued

0.288 for the man; In Step 4, the average correlation factor equals 0.718 for the woman and 0.467 for the man. On the contrary, correlation factors between the average degree of risk aversion of the woman and the average degree of risk aversion of the man are either weakly positive or negative depending on the considered step(s): In Step 3 (respectively Step 4), the correlation factor between the average degrees of risk aversion of the two spouses equals -0.125 (respectively -0.148 ); The correlation factor between the average degree of risk aversion of the woman in Step 3 and the average degree of risk aversion of the man in Step 4 equals -0.046; The correlation factor between the average degree of risk aversion of the woman in Step 4 and the average degree of risk aversion of the man in Step 3 equals 0.118.

17 In controlled experiments in which subjects have confronted exactly the same choice problem on two occasions, the proportion of choice reversals is between 10 and 30\%. See Table 1 in Stott (2006, p. 105).
} 
Table 4 Regression of the couple CARA level on the individual weighted average CARA levels

\begin{tabular}{|c|c|c|c|c|c|c|}
\hline \multirow[t]{2}{*}{ Series } & \multicolumn{3}{|c|}{ Case 1 ( 22 couples) } & \multicolumn{3}{|c|}{ Case 2 (17 couples) } \\
\hline & Woman & Man & Joint & Woman $=\mathrm{UC}$ & Man $=$ No UC & Joint \\
\hline 7 & $0.13(0.14)$ & $0.20(0.12)$ & $3.77(0.15)$ & $0.22(0.11)$ & $0.19(0.16)$ & $4.32(0.11)$ \\
\hline 8 & $0.03(0.55)$ & $0.25^{\boldsymbol{\Lambda}}(0.00)$ & $8.41^{\Delta}(0.02)$ & $0.07(0.34)$ & $0.24 \bowtie(0.01)$ & $8.52^{\triangle}(0.02)$ \\
\hline 9 & $0.24^{\Delta}(0.02)$ & $0.40^{\triangle}(0.02)$ & $8.94^{\triangle}(0.02)$ & $0.34^{*}(0.06)$ & $0.35^{*}(0.06)$ & $6.69^{\triangle}(0.04)$ \\
\hline 10 & $0.34^{\Delta}(0.02)$ & $0.56^{\triangle}(0.02)$ & $8.10^{\Delta}(0.02)$ & $0.93^{\star}(0.00)$ & $0.32 *(0.08)$ & $18.06^{\boldsymbol{\Lambda}}(0.00)$ \\
\hline 11 & $0.27^{\triangle}(0.05)$ & $0.21(0.31)$ & $4.16(0.13)$ & $0.66^{\mathbf{\Lambda}}(0.00)$ & $0.01(0.97)$ & $12.11^{\boldsymbol{\Delta}}(0.00)$ \\
\hline 12 & $0.11(0.16)$ & $0.14(0.26)$ & $2.72(0.26)$ & $0.24^{\triangle}(0.05)$ & $0.07(0.63)$ & $3.86(0.15)$ \\
\hline
\end{tabular}

Notes: $\mathbf{\Lambda}, \triangle, *$ indicate significance at 1,5 , and $10 \%$ level, respectively

Two-sided $p$-values in parentheses

levels. With a normal distribution, we obtain an unbiased estimate $\hat{\theta}_{j k}$ of $\tilde{\theta}_{j k}$ which, in turn, enables us to compute an unbiased estimate of $\theta_{k}$. Average individual risk aversion levels are based on the weighted mean of the absolute risk aversions estimated for each of the first six investment series: $\hat{\theta}_{k}=\sum_{j=1}^{6}\left(\left(\hat{\theta}_{j k}-\hat{\delta}_{j}\right) / \hat{\sigma}_{j}\right) / \sum_{j=1}^{6}\left(1 / \hat{\sigma}_{j}\right)$. The weights, inversely proportional to the estimated standard deviation of the residuals, improve the efficiency of the estimate when the variance of the residuals varies across series.

In order to study the evolution of the balance of power within the household, we use the individual risk aversions estimated from choices made in the first section of the experiment to explain the couple risk aversions estimated from choices made in the second section of the experiment. Concretely, we regress the couple CARA level on the respective spouses weighted average CARA levels for the different investment series of the second section of the experiment. Regressions are conducted on the entire sample (Case 1) and on the restricted sample composed of couples in which women ultimately implemented the joint decisions (Case 2). Our regression results, for each investment series of the second section of the experiment, are displayed in Table 4 where, in columns "Joint," we report the $\chi^{2}$-statistic of the likelihood test for the null hypothesis that both coefficients are zero. ${ }^{18}$

According to the regression results for Case 1, neither the man nor the woman weighted average CARA level significantly influences the couple CARA level in the seventh investment series. This observation suggests that spouses needed to acquire some experience in making investment choices jointly. The influence of the man risk aversion on the couple risk aversion is highly significant in investment series 8 , it becomes significant in investment series 9 and 10, and it is non-significant in the last two investment series. On the contrary, the influence of the woman risk aversion on the couple risk aversion is not significant in investment series 8 , but it is significant in investment series 9,10 , and 11 . These observations indicate that women gain more and more power over the course of decision making to the detriment of men.

\footnotetext{
18 In the Table 4, we report separate regressions for the different investment series. Running a single regression on the pooled data with interaction terms between investment series and individual measures of risk aversion produces qualitatively equivalent results.
} 
The balance of power within the household evolves even more clearly in couples where women ultimately implement the joint decisions. According to the regression results for Case 3, the influence of the man risk aversion on the couple risk aversion is highly significant in investment series 8 , it becomes weakly significant in investment series 9 and 10, and it is non-significant in the last two investment series. On the contrary, the influence of the woman risk aversion on the couple risk aversion is not significant in investment series 8 , it is weakly significant in investment series 9 , it becomes highly significant in investment series 10 and 11, and it is still significant in the last investment series. In addition, the marginal impact of the woman risk aversion is identical to the marginal impact of the man risk aversion in investment series 9 (where both are weakly significant), but it is three times higher in investment series 10 (where the man risk aversion is weakly significant, and the woman risk aversion is highly significant). Finally, the marginal impact of the woman risk aversion decreases in the last two investment series (where the man risk aversion is not significant). ${ }^{19}$

Our estimation results suggest that in most couples men have, initially, a stronger decision-making power than women. This observation is in line with earlier studies which show that men tend to have more say in economic decision making and readier access to financial resources than their wives (e.g., Pahl 1995; Kirchler et al. 2001). More surprisingly, our estimation results also suggest that, far from being fixed, decision-making powers are malleable. Women who ultimately implement the joint decisions gain more and more decision-making power over the course of an experimental session. ${ }^{20}$ Our evidence on the malleability of the balance of power within the household is clearly at odds with the collective approach based on static models of intra-household resource allocation that obeys a Pareto-efficient sharing rule. However, recent extensions of the collective approach to intertemporal settings where the assumption of intra-household commitment is relaxed allow for temporal variations in relative decision-making power (see, e.g., Mazzocco 2007). In a more drastic departure from the early collective approach, Basu (2006) discusses a model of household behavior under no-commitment where Pareto weights depend on choices variables. As a consequence, the Pareto weight assigned to each spouse is endogenous to the household decision-making process, i.e., the household balance of power is endogenously determined. The assumption of an endogenous intra-household balance of power has received empirical support by Lancaster et al. (2006) whose findings using household-level unit record data sets from India indicate that decision-making powers are determined jointly with the expenditure outcomes.

Although these recent extensions of the collective approach assume that intra-household allocations influence the balance of power within the household, they are not fully consistent with our experimental results since they predict that house-

\footnotetext{
19 Regression of the couple safe choices on the individual safe choices leads to similar results for the subset of investment series where the couple and individual choices can be directly compared. See Table 6 in the Appendix.

20 Note that we do not argue that women gain more decision-making power only because they ultimately implement the joint decisions, as it could well be that women ultimately implement the joint decisions because they initially have substantial decision-making power. We do, however, believe that there is a relative gain in decision-making power obtained by the spouse who ultimately implements the couple decisions.
} 
hold decisions shape relative decision-making power gradually. On the contrary, we observe that power patterns within the household vary quickly, which suggests that the household decision process heavily depends on the context. This observation might cause discomfort to economists, but it is fully in line with the social-exchange formulation of family power dynamics in social psychology and recent evidence from the marketing literature. According to the social-exchange perspective, decision-making power resides in the characteristics of relationships and not in personal traits which implies that power patterns within families will vary from time to time and with task characteristics (Beckman-Brindley and Tavormina 1978). Su et al. (2003) examine the dynamics of spousal behavioral interactions in a questionnaire study based on a sequence of family purchase decisions. Their results suggest that spousal purchasedecision processes are adaptive. In early purchase episodes, few spouses are willing to yield when faced with coercion while, in later purchase episodes, spouses get their way by strong means of influence. The authors speculate that there is a learning curve underlying the spousal decision-behavior dynamics.

Before concluding, we provide in the next section a quantitative analysis of the couples discussions which corroborates our previous analyzes of the choice data. ${ }^{21}$

\section{Quantitative analysis of the discussions within the couple}

In this section, we present a basic quantitative analysis of the discussions that couples had while answering investment series 7-12 (a content analysis is beyond the scope of the present study). Two undergraduate native raters independently watched the videos of 17 couples several times and evaluated the talk duration of each spouse, i.e., the amount of time spent by each spouse talking to the other spouse about which joint decision to implement. ${ }^{22}$ Both raters were instructed to exclude from talk duration the amount of time spent by each spouse discussing topics not closely related to the experiment. Table 5 shows the individual talk durations per investment series as well as the ratio between the woman talk duration (WTD) and the couple talk duration (CTD) for each of the 17 couples.

In all these couples except two, the man was always arguing more about which joint decision to implement than the woman. Unsurprisingly, both spouses talk on average more in the seventh investment series than in the latter investment series. Although there is no clear time trend in WTDs, men argue on average more in the first three investment series than in the last three investments series. It seems natural to relate the talk duration of an individual with his/her decision-making power: the more an individual is arguing the more he/she is trying to influence the joint decision (and, in most cases, he/she will probably be successful). In this respect, our quantitative analysis of the couples discussions corroborates our statistical analyzes of the choice data: the man leads the joint decision, at least initially. Our previous analyzes also suggested that the woman who ultimately implements the joint decisions gains power over the

\footnotetext{
21 Verbal frequency measures constitute the main quantitative process measures to study family interactions in psychology. See, e.g., Jacob (1975) and the references therein.

22 Unfortunately, five out of the 22 videos had to be discarded due to the low sound quality.
} 
Table 5 Individual talk durations in seconds

\begin{tabular}{|c|c|c|c|c|c|c|c|c|c|c|}
\hline \multirow[t]{2}{*}{ Session } & \multirow[t]{2}{*}{ Cabin } & \multirow[t]{2}{*}{ Spouse } & \multicolumn{6}{|c|}{ Investment series } & \multirow[t]{2}{*}{ Total } & \multirow[t]{2}{*}{ WTD/CTD } \\
\hline & & & 7 & 8 & 9 & 10 & 11 & 12 & & \\
\hline January 24, 2005 & 1 & Man & 45 & 40 & 28 & 35 & 43 & 25 & 216 & 0.388 \\
\hline $7 \mathrm{pm}$ & & Woman & 35 & 30 & 20 & 10 & 23 & 19 & 137 & \\
\hline January 24, 2005 & 2 & Man & 55 & 60 & 60 & 34 & 38 & 23 & 270 & 0.338 \\
\hline $7 \mathrm{pm}$ & & Woman & 40 & 25 & 18 & 15 & 29 & 11 & 138 & \\
\hline January 25, 2005 & 1 & Man & 29 & 19 & 11 & 10 & 24 & 25 & 118 & 0.433 \\
\hline $7 \mathrm{pm}$ & & Woman & 20 & 13 & 12 & 6 & 24 & 15 & 90 & \\
\hline January 25, 2005 & 2 & Man & 44 & 33 & 50 & 27 & 37 & 12 & 203 & 0.450 \\
\hline $7 \mathrm{pm}$ & & Woman & 23 & 18 & 49 & 17 & 44 & 15 & 166 & \\
\hline January 25, 2005 & 3 & Man & 44 & 38 & 36 & 14 & 20 & 37 & 189 & 0.357 \\
\hline $7 \mathrm{pm}$ & & Woman & 20 & 14 & 11 & 6 & 20 & 34 & 105 & \\
\hline January 25,2005 & 4 & Man & 8 & 18 & 26 & 17 & 28 & 8 & 105 & 0.521 \\
\hline $7 \mathrm{pm}$ & & Woman & 16 & 14 & 17 & 23 & 28 & 16 & 114 & \\
\hline January 26, 2005 & 1 & Man & 25 & 20 & 22 & 30 & 31 & 36 & 164 & 0.416 \\
\hline $7 \mathrm{pm}$ & & Woman & 20 & 9 & 21 & 20 & 21 & 26 & 117 & \\
\hline January 26, 2005 & 2 & Man & 52 & 13 & 29 & 30 & 20 & 8 & 152 & 0.290 \\
\hline $7 \mathrm{pm}$ & & Woman & 26 & 8 & 5 & 6 & 11 & 6 & 62 & \\
\hline January 26, 2005 & 3 & Man & 4 & 3 & 7 & 3 & 31 & 17 & 65 & 0.356 \\
\hline $7 \mathrm{pm}$ & & Woman & 3 & 8 & 4 & 4 & 6 & 11 & 36 & \\
\hline January 27, 2005 & 2 & Man & 13 & 9 & 11 & 14 & 21 & 10 & 78 & 0.447 \\
\hline $7 \mathrm{pm}$ & & Woman & 13 & 7 & 7 & 9 & 14 & 13 & 63 & \\
\hline January 27, 2005 & 3 & Man & 70 & 51 & 42 & 43 & 34 & 28 & 268 & 0.396 \\
\hline $7 \mathrm{pm}$ & & Woman & 46 & 25 & 14 & 32 & 42 & 17 & 176 & \\
\hline January 28, 2005 & 1 & Man & 51 & 44 & 21 & 19 & 19 & 31 & 185 & 0.387 \\
\hline $7 \mathrm{pm}$ & & Woman & 26 & 19 & 24 & 15 & 18 & 15 & 117 & \\
\hline January 28, 2005 & 2 & Man & 24 & 34 & 25 & 24 & 34 & 25 & 166 & 0.362 \\
\hline $7 \mathrm{pm}$ & & Woman & 24 & 6 & 17 & 23 & 11 & 13 & 94 & \\
\hline February 19, 2005 & 1 & Man & 38 & 11 & 13 & 16 & 20 & 29 & 127 & 0.392 \\
\hline $3 \mathrm{pm}$ & & Woman & 24 & 8 & 10 & 12 & 9 & 19 & 82 & \\
\hline February 19, 2005 & 2 & Man & 48 & 30 & 22 & 30 & 30 & 35 & 195 & 0.449 \\
\hline $3 \mathrm{pm}$ & & Woman & 36 & 34 & 18 & 27 & 19 & 25 & 159 & \\
\hline February 19, 2005 & 3 & Man & 42 & 20 & 8 & 3 & 6 & 10 & 89 & 0.429 \\
\hline $3 \mathrm{pm}$ & & Woman & 20 & 7 & 11 & 8 & 5 & 16 & 67 & \\
\hline February 19, 2005 & 2 & Man & 20 & 18 & 10 & 6 & 28 & 20 & 102 & 0.512 \\
\hline $5 \mathrm{pm}$ & & Woman & 23 & 16 & 12 & 7 & 34 & 15 & 107 & \\
\hline
\end{tabular}

Note: WTD/CTD denotes the ratio between the woman talk duration and the couple talk duration

course of decision making to the detriment of the man. We offer now a final evaluation of the impact of ultimate control on the evolution of power balance by comparing the woman relative talk duration when she has ultimate control to her relative talk duration when the man has ultimate control. Figure 3 shows the woman relative talk duration in each investment series averaged, on the one hand, over the 13 couples where the 


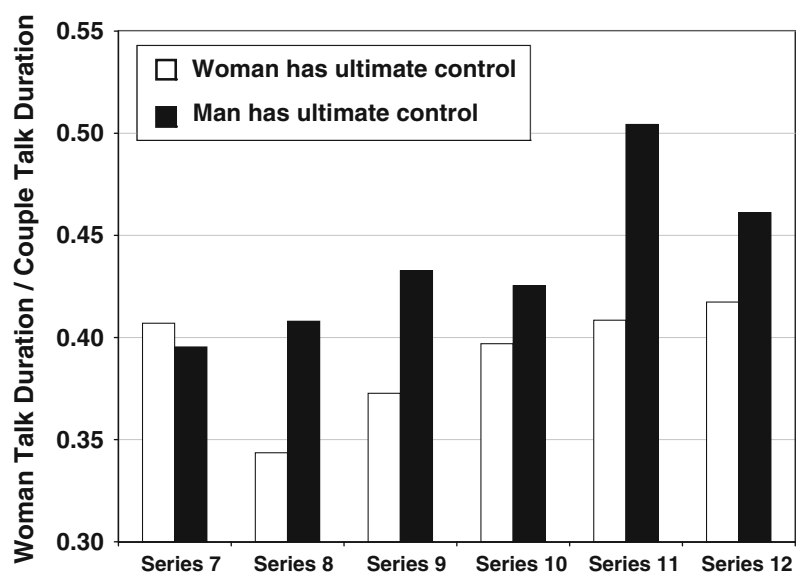

Fig. 3 Woman relative talk duration

woman had ultimate control and averaged, on the other hand, over the 4 couples where the man had ultimate control.

In the seventh investment series, whether the woman has ultimate control or not does not influence her talk duration. However, in investment series 8 and 9, a woman without ultimate control argues, in relative terms, much more than a woman who has ultimate control. A similar tendency is observed in the last part of the experimental session, i.e., in investment series 10-12. Under the natural assumption that talk duration is related to decision-making power, we again conclude that the spouse who has ultimate control gains additional influence on the decision of the couple.

\section{Concluding comments}

This article reports results on individual and couple choices in an experiment involving risk. Individuals and couples make binary choices between a lottery and a sure payoff. In the first part of the experiment, spouses are separated and choose independently. Individual choices express individual risk preferences. In the second part of the experiment, male spouses rejoin their partner, and they make joint choices. In most cases, the woman implemented the couple choices which express collective risk preferences. We investigate the evolution of the balance of power within the household by the individual risk aversions estimated from choices made in the first section of the experiment to explain the couple risk aversions estimated from choices made in the second section of the experiment. We find that the man is initially more successful than the woman in influencing couple choices but that the woman progressively gains power over the course of decision making, and we speculate that part of this power increase relates to the ultimate control over the implementation of joint choices.

Our evidence on the dynamics of power balance suggests that actual decision processes within the household are adaptive and depend on the context. This finding contradicts the early collective approach based on static models of intra-household 
resource allocation according to which the decision-making powers are regarded as exogenous to the household decision-making process. It is, however, compatible with recent extensions of the collective approach, which assume that intra-household allocations influence the balance of power within the household. More research on larger samples would be necessary to validate this preliminary finding. Similarly, larger samples would be necessary to link stated and revealed decision-making power to distribution factors (such as difference between spouses, educational levels, ages, or assets).

Acknowledgments Many thanks are due to two constructive and helpful referees whose comments improved this article considerably. We are especially grateful to one of the referees who encouraged us to develop our ideas more fully. Research assistance has been provided by Sascha Bähr, Andreas Dittrich, Hendrik Ehrhardt, Andreas Lehmann, Anika Littmann, Dirk Pogode, Christoph Röber, and Torsten Wollina. We acknowledge the financial and technical supports from the Institut National d'Etudes Démographiques, and the French National Research Agency (research program "RiskAttitude", ref. ANR-05-BLAN-0345-01). Valuable suggestions were provided by seminar participants at the University of Virginia, Cergy-Pontoise (THEMA), Paris I, Paris II (ERMES), and Montpellier, and at INED, as well as by the members of the RiskAttitude consortium. We especially thank Olivier Donni for very useful discussions about the literature on collective models.

Open Access This article is distributed under the terms of the Creative Commons Attribution Noncommercial License which permits any noncommercial use, distribution, and reproduction in any medium, provided the original author(s) and source are credited.

\section{Appendix: Dynamics of power balance in the ordinal approach}

Contrary to the regression results reported in Table 4, the regression results reported in the table below are based on a subset of the observed choices, namely the individual choices made in investment series 4-6 (Step 4) and the couple choices made in investment series 7-9 (Step 5).

Table 6 Regression of couple safe choices on individual safe choices

\begin{tabular}{|c|c|c|c|c|c|c|}
\hline \multirow[t]{2}{*}{ Series } & \multicolumn{3}{|c|}{ Case 1 (22 couples) } & \multicolumn{3}{|c|}{ Case 2 (17 couples) } \\
\hline & Woman & Man & Adjusted $R^{2}$ & Woman $=\mathrm{UC}$ & Man $=$ No UC & Adjusted $R^{2}$ \\
\hline 7 & $0.15(0.19)$ & $0.33^{\Delta}(0.03)$ & 0.24 & $0.25(0.12)$ & $0.34^{\triangle}(0.03)$ & 0.36 \\
\hline 8 & $0.15(0.23)$ & $0.37^{\Delta}(0.03)$ & 0.15 & $0.38^{\mathbf{\Lambda}}(0.01)$ & $0.41 \triangleleft(0.01)$ & 0.50 \\
\hline 9 & $0.25^{\Delta}(0.05)$ & $0.11(0.43)$ & 0.11 & $0.29 *(0.10)$ & $0.07(0.70)$ & 0.07 \\
\hline
\end{tabular}

Notes: $\boldsymbol{\Lambda}, \Delta, *$ indicate significance at 1,5 , and $10 \%$ level, respectively

Two-sided $p$-values in parentheses

\section{References}

Basu, K. (2006). Gender and say: A model of household behavior with endogenously determined balance of power. Economic Journal, 116, 558-580. 
Bateman, I., \& Munro, A. (2005). An experiment on risky choice amongst households. Economic Journal, 115, C176-C189.

Bateman, I., \& Munro, A. (2009). Household versus individual valuation: What's the difference? Environmental and Resource Economics, 43, 119-135.

Beckman-Brindley, S., \& Tavormina, J. (1978). Power relationships in families: A social-exchange perspective. Family Process, 17, 423-436.

Bruner, D., McKee, M., \& Santore, R. (2008). Hand in the cookie jar: An experimental investigation of equity-based compensation and managerial fraud. Southern Economic Journal, 75, 261-278.

Chiappori, P. A. (1988). Rational household labor supply. Econometrica, 56, 63-90.

Cubitt, R., Starmer, C., \& Sugden, R. (1998). On the validity of the random lottery incentive system. Experimental Economics, 1, 115-131.

Donni, O. (2003). Collective household labor supply: Nonparticipation and income taxation. Journal of Public Economics, 87, 1179-1198.

Duflo, E. (2003). Grandmothers and granddaughters: Old age pension and intra-household allocation in South Africa. World Bank Economic Review, 17, 1-25.

Eckel, C., \& Wilson, R. (2004). Is trust a risky decision? Journal of Economic Behavior \& Organization, 55, 447-465.

Harrison, G., \& List, J. (2004). Field experiments. Journal of Economic Literature, 42, 1013-1059.

Hey, J., \& Lee, J. (2005). Do subjects separate (or are they sophisticated)? Experimental Economics, 8, 233-265.

Hey, J., \& Orme, C. (1994). Investigating generalizations of expected utility theory using experimental data. Econometrica, 62, 1291-1326.

Holt, C. (1986). Preference reversals and the independence axiom. American Economic Review, 76, 508513.

Holt, C., \& Laury, S. (2002). Risk aversion and incentive effects. American Economic Review, 92, 16441655 .

Jacob, T. (1975). Family interaction in disturbed and normal families: A methodological and substantive review. Psychological Bulletin, 82, 33-65.

Kirchler, E., Rodler, C., Holzl, E., \& Meier, K. (2001). Conflict and decision making in close relationships. Hove: The Psychology Press.

Lancaster, G., Maitra, P., \& Ray, R. (2006). Endogenous intra-household balance of power and its impact on expenditure patterns: Evidence from india. Economica, 73, 435-460.

Lechner, M. (2001). The empirical analysis of East German fertility after unification: An update. European Journal of Population, 17, 61-74.

Mazzocco, M. (2004). Savings, risk sharing and preferences for risk. American Economic Review, 94, 11691182.

Mazzocco, M. (2007). Household intertemporal behaviour: A collective characterization and a test of commitment. Review of Economic Studies, 74, 857-895.

Munro, A., Bateman, I., \& McNally, T. (2008). The family under the microscope: An experiment testing economic models of household choice. MPRA Paper No. 8974.

Pahl, J. (1995). His money, her money: Recent research on financial organisation in marriage. Journal of Economic Psychology, 16, 361-376.

Starmer, C., \& Sugden, R. (1991). Does the random-lottery incentive system elicit true preferences? An experimental investigation. American Economic Review, 81, 971-978.

Stott, H. (2006). Cumulative prospect theory's functional menagerie. Journal of Risk and Uncertainty, 32, 101-130.

Su, C., Fern, E., \& Ye, K. (2003). A temporal dynamic model of spousal family purchase-decision behavior. Journal of Marketing Research, 40, 268-281.

Vermeulen, F. (2002). Collective household models: Principles and main results. Journal of Economic Surveys, $16,533-564$. 